Relations industrielles

Industrial Relations

\title{
B.I.T. : La liberté syndicale - Manuel d'éducation ouvrière. (2e éd.), Genève, Bureau international du travail, 1988, 153 pp., ISBN 92-2-205782-1
}

\section{Pierre Verge}

\section{Volume 43, numéro 3, 1988}

URI : https://id.erudit.org/iderudit/050443ar

DOI : https://doi.org/10.7202/050443ar

Aller au sommaire du numéro

\section{Éditeur(s)}

Département des relations industrielles de l'Université Laval

ISSN

0034-379X (imprimé)

1703-8138 (numérique)

Découvrir la revue

Citer ce compte rendu

Verge, P. (1988). Compte rendu de [B.I.T. : La liberté syndicale - Manuel d'éducation ouvrière. (2e éd.), Genève, Bureau international du travail, 1988 , 153 pp., ISBN 92-2-205782-1]. Relations industrielles / Industrial Relations, 43(3), 712-713. https://doi.org/10.7202/050443ar

Tous droits réservés @ C Département des relations industrielles de l'Université Laval, 1988
Ce document est protégé par la loi sur le droit d'auteur. L’utilisation des services d’Érudit (y compris la reproduction) est assujettie à sa politique d'utilisation que vous pouvez consulter en ligne.

https://apropos.erudit.org/fr/usagers/politique-dutilisation/ 
alors, tous ces bons arguments n'indiquent-ils pas, plus directement, que le droit de grève n'est pas un de ces droits «économiques et sociaux»? De toute façon, quelle est la portée pratique, ici, d'une telle qualification? Certainement pas celle qui s'attache à la définition de la compréhension de la liberté d'association. Comme le lecteur canadien aura été à même de le constater à la suite de la trilogie de la Cour suprême de 1987, celle-ci est susceptible de variations judiciaires de grande amplitude, au point d'inclure ou non le droit de grève...

Quoi qu'il en soit, nous demeurons en présence d'une synthèse fort lucide du droit international relatif à la grève.

Pierre VERGE

Université Laval

La liberté syndicale - Manuel d'éducation ouvrière, deuxième édition (révisée), Genève, Bureau international du travail, 1988, 153 pp., ISBN 92-2-205782-1

La protection des droits syndicaux demeure l'une des activités capitales de l'O.I.T., nous rappelle dans sa préface le directeur général du B.I.T., monsieur Francis Blanchard. Le présent ouvrage, en somme, constitue une synthèse de l'activité de l'organisme à ce sujet: formulation normative et jurisprudentielle des exigences concrètes de la liberté syndicale, aperçu des voies de recours destinées à assurer sa protection, de même que, en annexe, les passages les plus fondamentaux des grands instruments de l'O.I.T. en matière de liberté syndicale. Il s'agit là de la reformulation d'une présentation antérieure, datant de 1959 et largement diffusée en plusieurs langues. Ces quelque trente ans ont d'ailleurs amené, en particulier, une multiplication des plaintes au Comité de la liberté syndicale, créé en 1951 par le Conseil d'administration du B.I.T.: signe, non seulement de résistances et de combats tenaces auxquels donne encore lieu, dans bien des pays, l'affirmation de la liberté syndicale, mais aussi, pour reprendre à nouveau les propos de monsieur Blanchard, signe de la complexité de cette liberté, du moins dans son application concrète et diverse: droits des fonctionnaires, des travailleurs migrants, pour ne citer que deux exemples courants.

Le contenu (et le ton) de ce «manuel d'éducation ouvrière» demeure celui d'autres publications que le B.I.T. a consacrées à la liberté syndicale. Il n'y a pas lieu de s'en surprendre, car le substrat est nécessairement le même, soit les passages fondamentaux pertinents de la Constitution de l'O.I.T. et le libellé de ses conventions et recommendations traitant de la liberté syndicale, en particulier la Convention (no 87) sur la liberté et la protection du droit syndical, de 1948, qui affirme celle-ci face à l'État, et la Convention (no 98) sur le droit d'organisation et de négociation collective, adoptée l'année suivante, qui traite du droit syndical des travailleurs au regard des employeurs, de même que de la protection des organisations de travailleurs et des organisations d'employeurs les unes par rapport aux autres. On se retrouve ici assez bien devant la somme des énoncés de principe dégagés par le Comité de la liberté syndicale, qui ont fait l'objet d'un compendium également publié par le B.I.T. sous le titre: Liberté syndicale (troisième édition, 1985), les références précises aux différentes recommandations de ce Comité en moins. Nous ne sommes pas tellement loin, non plus, des vues du rapport de la Commission d'experts pour l'application des conventions et recommandations traitant du même sujet (Liberté syndicale et négociation collective, 1983).

Après un rappel des origines, des traits caractéristiques et de la mission de l'O.I.T., un premier chapitre précise la nature et la portée des instruments internationaux du travail et identifie ceux qui intéressent la liberté syndicale. Le chapitre suivant est entièrement consacré à la 
description des modes de contrôle de l'application des normes internationales du travail, avec, naturellement, une insistance sur les organes spécifiques voués à la protection de la liberté syndicale: la Commission d'investigation et de conciliation en matière de liberté syndicale et le Comité de la liberté syndicale, dont on précise la procédure et la portée des recommandations. La connaissance de ces données liminaires permet ensuite d'envisager le contour précis de la liberté syndicale ainsi défini au niveau international, ce à quoi sont consacrés les sept autres chapitres: la généralité de l'affirmation de la liberté syndicale et la situation particulière de certaines catégories professionnelles, dont les fonctionnaires et les travailleurs agricoles; au regard de la Convention no 87, la liberté constitutive de syndicats, "sans autorisation préalable» des pouvoirs publics à la liberté d'appartenance des travailleurs et des employeurs à des organisations «de leur choix», ce qui conduit à traiter du monopole syndical; la liberté de fonctionnement des organisations, tant en ce qui a trait à leurs règles internes, au choix de leurs dirigeants et à la détermination de leurs structures, qu'au droit «... d'organiser leur gestion et leur activité et de formuler leur programme d'action", énoncé de l'article 3 de cette Convention no 87, qui véhicule lui-même la définition de la liberté de grève et de ses limites, élément essentiel de la liberté syndicale. Cette liberté syndicale appelle une protection adéquate, celle des travailleurs contre des actes de discrimination syndicale - revêt ici une acuité particulière, le sort des dirigeants et délégués syndicaux: celle des organisations syndicales elles-mêmes, contre des actes d'ingérence. Par ailleurs: «(l')évolution du mouvement syndical montre que l'amélioration des conditions de travail par la négociation collective, tout en demeurant à l'évidence un axe fondamental de l'action syndicale, s'accompagne d'une participation croissante des organisations à la définition de la politique économique et sociale (p. 62)". Bien que l'on ne puisse ainsi réduire l'action syndicale à cette activité de négociation collective, celle-ci procède intimement du droit syndical, d'où cet avant-dernier chapitre traitant principalement de la reconnaissance des syndicats et de leur représentativité, du caractère volontaire, du niveau de la négociation collective et de la possibilité de sa subordination à la politique économique de l'État. Les droits syndicaux, enfin, sont illusoires si ne prévalent pas, plus généralement, les libertés publiques fondamentales, d'où ces considérations finales sur la sureté de la personne et les libertés de réunion, d'opinion et d'expression.

L'exposé de tout ce contenu résulte en synthèse claire et repolie des exigences précises de la liberté syndicale aux yeux de l'O.I.T., d'où sa valeur certaine. S'agit-il vraiment d'un manuel d'éducation ouvrière en la matière? L'accueil favorable réservé à la première édition, si l'on s'en tient à la présentation de l'ouvrage, imposerait une réponse affirmative. Nul doute, de plus, que cette synthèse peut nourrir bien des esprits, alimenter bien des discussions, du moins si les animateurs sont habiles... Mais, si l'on tient à cette vocation, ne faudrait-il pas faciliter une démarche active de la part de ceux qui veulent connaître le sujet: ajouter, par exemple, quelques études de cas (en dépit de la difficulté tenant au particularisme des contextes nationaux); soulever différentes questions à partir de quelques recommandations importantes du Comité de la liberté syndicale... Le texte évoque déjà un bon nombre d'exemples dans certains de ses passages (la page 78, pour illustrer); il s'agirait de les accentuer; de plus, la reproduction, intégrale ou partielle, en annexe, des conventions, recommandations et directives pertinentes représente déjà un acquis important.

Enfin, quant au contenu juridique lui-même, ressort, on ne peut mieux, encore une fois, la définition des exigences de la liberté syndicale sur le plan international. Nous apprenons également comment celle-ci s'impose aux différents États, toujours dans la perspective du droit international. Mais, afin de situer le travailleur dans le quotidien et de lui éviter ainsi des méprises, ne faudrait-il pas aussi tenter d'exposer sommairement (en dépit de la divergence des systèmes nationaux à cet égard) dans quelle mesure et de quelle façon ces normes internationales font, ou, au contraire, ne font pas intégralement partie du droit interne?

Pierre VERGE 